\title{
Assessing the Impact of Algae Management Strategies on Anurans and Aquatic Communities
}

Courtney Dvorsky ( $\square$ dvorskc2@miamioh.edu )

Miami University

Kambrie Riddle

Miami University

Michelle Boone

Miami University

\section{Research Article}

Keywords: Aquashade, Copper sulfate, Anuran, Management

Posted Date: June 16th, 2021

DOI: https://doi.org/10.21203/rs.3.rs-256287/v1

License: (1) This work is licensed under a Creative Commons Attribution 4.0 International License.

Read Full License 


\section{Abstract}

Residential areas are increasing on the landscape but their ability to provide suitable habitat is often based on management for recreational use and aesthetics. Amphibians rely on both aquatic and terrestrial habitat making them susceptible to changes in land-cover and land-use. As anthropogenic land-use change increases, it is imperative to assess how pond management practices impact aquatic communities. We assessed the impact of Aquashade (a common non-toxic pond dye) and copper sulfate (a toxic algaecide) on American toad (Anaxyrus americanus), northern leopard frog (Lithobates pipiens), and Cope's gray treefrog (Hyla chrysoscelis) metamorphosis in outdoor mesocosm experiments. We also evaluated the relative impact of tadpole grazing and chemical treatment on phytoplankton and periphyton abundance. We found no significant effects of pond management treatment on anuran metamorphosis, suggesting that addition of Aquashade and copper sulfate does not significantly impact anurans under these experimental conditions. However, while we found no differences in phytoplankton and periphyton abundance due to pond management treatment, presence of tadpoles significantly decreased phytoplankton and periphyton abundance over time. This result suggests that the creation of suitable pond habitat for anuran tadpoles may be an efficient and ecologically beneficial form of pond management treatment to maintain water quality.

\section{Introduction}

Loss of wetlands poses a major threat to aquatic species; however, local creation of ponds and wetlands has been generally increasing in residential areas having the potential to restore habitat to maintain native biodiversity. Residential development has increased with human population growth further extending the impacts of anthropogenic change on the landscape (McKee et al. 2003; Theobald 2004; Ewers and Didham 2006). For instance, Smith et al. (2002) found that at least 2.6 million small, humanmade ponds have been created in the conterminous U.S., and these impoundments are a major sink for sediments (Renwick et al. 2005). Nevertheless, the management of new pond habitat can vary drastically based on individual preferences in aesthetics, recreational use, and cost (Blaine et al. 2012), positively or negatively altering habitat quality and biodiversity potential (Hansen 2005; Cushman 2006; Urban and Roehm 2018). Given that residential land-use is increasing, it is imperative to determine the impact of management practices on aquatic communities and local species that inhabit them (Locke et al. 2019).

Large-lot residential areas are desirable for landowners looking for residential space with increased exposure to wildlife and recreational area (Brown et al. 2005; Blaine et al. 2012; Robinson 2012). While residential development increases habitat fragmentation, it can alternatively improve habitat suitability for native flora and fauna through pond creation and increased habitat heterogeneity (Urban and Roehm 2018). However, the habitat suitability of large lot residential lands will depend on the management practices of individual landowners. For instance, Goldberg and Waits (2009), found that over $50 \%$ of landowners surveyed stocked their ponds with fish for recreational use, which would alter aquatic food webs and eliminate or reduce diversity of taxa like amphibians that are sensitive to fish predation (Walston and Mullin 2007; Vonesh et al. 2009; Ade et al. 2010). Furthermore, landowners may choose to 
use chemical management to decrease aquatic vegetation and improve lawn aesthetics even though this may increase nitrogen and phosphorus loads on the landscape and negatively impact aquatic ecosystems (Loman and Lardner 2006; Peltzer et al. 2008; Carey et al. 2013; Martini et al. 2015). Blaine et al. (2012) found that $73 \%$ of surveyed landowners use chemical management and moreover the amount of chemicals applied is higher in residential areas compared to agriculture counterparts. Given the increase in residential areas it is imperative to determine the impact of common residential chemical management on aquatic communities.

Aquashade and copper sulfate are two common chemicals used to manage residential ponds suffering from aquatic plant overgrowth (Lynch 2009). Copper sulfate has historically been used to directly decrease algal growth, although it is known to be toxic to other aquatic organisms (Lynch 2009; Garcia Munoz et al. 2009; U.S. EPA. 2013). Two studies on northern leopard frog (Rana pipiens) tadpoles, found that when exposed to copper sulfate concentrations $>0.15 \mathrm{ppm}$, mortality significantly increased (Lande and Guttman 1973; Chen et al. 2007). Additionally, when exposed to $>0.20$ ppm copper sulfate, Garcia Munoz et al. (2009) found Natterjack toad (Epidalea calamita) tadpoles had significantly decreased growth compared to control toads, but the timing of copper sulfate application mattered. For example, larval anurans exposed at Gosner stage 25 had increased time to metamorphosis and exhibited significant physiological impairments such as edema, resulting in high mortality (Carvalho and Fernandes 2006; Chen et al. 2007; Gurkan and Hayretdag 2012).

Aquashade is a non-toxic, pond dye that blocks photosynthetic light and indirectly controls aquatic plant growth (U.S. EPA. 2005; Suski et al. 2018). Though Aquashade was non-toxic when applied to an entire lake ecosystem at $1.5 \mathrm{ppm}$, Aquashade decreased aquatic photic depth by $50 \%$, phytoplankton biomass by $60 \%$, and zooplankton biomass by $55 \%$ (Batt et al. 2015). Contrastingly, Aquashade applied at the recommended dose $(2.0 \mathrm{ppm})$ in a small-scale mesocosm experiment resulted in no change in phytoplankton biomass and an increase in zooplankton abundance; however, species composition became less diverse with Aquashade exposure (Suski et al. 2018). Ludwig et al. (2010) found Aquashade applied at twice the recommended dose $(4.0 \mathrm{ppm})$ had no direct impact on several fish species' fingerling abundance, weight, or survival. While these results suggest that Aquashade could be an effective product for aquatic plant management, information about effects to other non-target aquatic organisms, including amphibians, is lacking and needs further investigation.

Phytoplankton and periphyton are essential in bottom-up aquatic ecosystem processes; therefore, it is important to understand how various management strategies impact aquatic resources and communities (Mallory and Richardson 2005; Rowland 2017). While herbicides are often chosen to decrease aquatic plant growth, they can indirectly and negatively impact larval anurans by limiting their primary food resource (Loman 2001; Boone and James 2003; Relyea 2005). Native biological control offers another option for controlling overproduction of algae. Because tadpoles graze on both phytoplankton and periphyton (Dickman 1968; Loman 2001; Pryor 2003), tadpoles could provide a natural form of algal bioremediation (Rowland 2017). 
We conducted two experiments to determine the effects of algal management using Aquashade and copper sulfate on anuran metamorphosis. Additionally, to determine how tadpole presence compared with chemical management on the impact of phytoplankton and periphyton abundance, we exposed ponds to Aquashade, copper sulfate, and tadpoles. We hypothesized that addition of pond management treatments (chemical addition) would negatively impact anuran metamorphosis resulting in decreased survival, decreased mass at metamorphosis, and increased time to metamorphosis, and that chemical addition would reduce phytoplankton, periphyton, and zooplankton abundance. We predicted that Aquashade would indirectly impact anuran metamorphosis through reduced food resources (phytoplankton and periphyton abundance) due to a darkening effect from dye application; whereas, we predicted that the toxicity of copper sulfate would have a direct negative impact on anuran metamorphosis. Furthermore, we predicted that tadpole grazing and chemical management, via Aquashade and copper sulfate application, would similarly reduce algal resources.

\section{Materials And Methods}

We collected nine partial northern leopard frog (Rana pipiens) egg masses from a vernal pool at Talawanda High School in Oxford, OH on 21-22-March-2017, seven partial American toad (Anaxyrus americanus) egg strings from Rush Run Wildlife Area in Somerville, OH on 6-April-2017, and six partial Cope's gray treefrog (Hyla chrysoscelis) egg masses from six breeding pairs at Miami University's Ecological Research Center (ERC) in Oxford, $\mathrm{OH}$ on May 27-28, 2017. We placed eggs in containers with natal pond water and brought them back to the lab in an environmental chamber at $23^{\circ} \mathrm{C}$ where they were monitored daily for hatching. Hatched tadpoles were placed in new containers of dechlorinated water and monitored daily until they reached free swimming stage, Gosner stage 25 (Gosner 1960). We changed the water in tadpole containers daily and fed tadpoles TetraMin fish flakes until they were added to outdoor mesocosms.

In 2017 , we set up a total of 50 aquatic communities in polyethylene cattle tank mesocosms ( $1.83 \mathrm{~m}$ in diameter, 1,480 L volume, Figure 1). We set up 25 mesocosms on 23-March-2017 for spring breeding species, and the remaining 25 on 23-May-2017 for summer breeding species (Figure 1a). On 24-March2017 and 24-May-2017 (spring and summer breeding, respectively), we filled polyethylene cattle tank mesocosms with $1000 \mathrm{~L}$ of Oxford city water, and on 25-March-2017 and 25-May-2017 added $1 \mathrm{~kg}$ of leaf litter (primarily Oak, Beech, and Maple trees) collected from a mixed deciduous forest in Miami University's Natural Areas. Lastly, we added water inoculated with zooplankton and algae from a pond located at the ERC to each mesocosm on 26, 28 and 30-March-2017 or 26, 28 and 30-May-2019. Tadpoles were added to mesocosms once they had reached the free-swimming stage, Gosner stage 25 (Gosner 1960). Specifically, in the spring breeding mesocosms, we added 30 northern leopard frog tadpoles on 1-April-2017 and 30 American toad tadpoles on 12-April-2017 (experimental day 0). We added 30 Cope's gray treefrog tadpoles to the summer breeding mesocosms on 10-June-2017. All mesocosms were covered with a screen lid $(2 \mathrm{~mm} \times 2 \mathrm{~mm}$ ) to prevent non-target species from entering the artificial community. 
In 2019, we conducted another study with four partial egg masses of Cope's gray treefrogs from four breeding pairs on 27, 28, and 29-May-2019 collected from the ERC. Based on the results from our initial experiment we chose to only include treefrogs to reduce experimental complexity and focus on additional aquatic community impacts. We set up a total of 24 aquatic communities on 27-May-2019 in mesocosms (Figure 1b) following the same methodology as in 2017. On 7-June-2019 (experimental day 0 ) we added 30 Cope's gray treefrog tadpoles to the 12 mesocosms randomly assigned to the tadpole management treatment to evaluate the impact of tadpole presence versus absence on the abundance of periphyton and phytoplankton separate from pond management treatments.

In 2017, we added Aquashade and copper sulfate ("pond management treatments") at two concentrations (high and low). The high concentration treatment was the recommended dose of each chemical, calculated to the volume of our cattle tank mesocosms $(1000 \mathrm{~L})$, and the low concentration treatment was half of the calculated recommended dose. We added $1.90 \mathrm{ppm}(\mathrm{mg} / \mathrm{L})$ and $0.95 \mathrm{ppm}$ of Aquashade, and $0.0392 \mathrm{ppm}$ and $0.0196 \mathrm{ppm}$ of copper sulfate as the high and low treatment, respectively. We applied each treatment by adding the measured amount of each chemical to a watering can filled with city tap water and distributed each evenly across the mesocosm; the watering can was rinsed clean in between each treatment application. Pond management treatments were applied to mesocosms one week after tadpole addition (19-April-2017 and 19-June-2017 respectively) to allow for tadpole acclimation. One-hour post dosing, we collected a $1 \mathrm{~L}$ sample of water from each cardinal direction in each mesocosm, which was further combined by treatment. From this solution we collected a $50 \mathrm{~mL}$ composite sample for each recommended dose treatment and sent the sample to Mississippi State University for chemical analysis to confirm our treatment dose. Results from chemical analysis conducted by Mississippi State University from the initial experiment, showed no detection of copper sulfate or tartrazine (a yellow dye in Aquashade); however, erioglaucine (a blue dye in Aquashade) was detected at $4.82 \mathrm{ppm}$.

In 2019, we added Aquashade and copper sulfate on 11-Jun-2019, at the recommended concentration (1.90 ppm Aquashade and $0.0392 \mathrm{ppm}$ copper sulfate), following methods used in 2017 . We used the recommended concentration due to our previous results not showing any treatment differences due to chemical concentration. Our experimental design included four pond management treatments and two tadpole treatments for six total treatments; each treatment had four mesocosm replicates, totaling 24 mesocosms in our design (Figure 1b). Twenty-four hours after pond management treatment addition, we collected a $1 \mathrm{~L}$ composite sample (instead of $50 \mathrm{ml}$ ) of each treatment (following methods in 2017) and sent it to Mississippi State University for chemical analysis. We collected a larger water sample for chemical analysis in this experiment to have a higher likelihood of detecting our treatment chemicals since they are at a relatively low concentration. Results from this chemical analysis showed copper sulfate detection at $0.031 \mathrm{ppm}$, erioglaucine detected at $0.392 \mathrm{ppm}$, and tartrazine was not detected. We collected another composite sample one week after initial treatment addition to determine if any degradation had occurred. Results from those samples sent to Mississippi State University detected $0.020 \mathrm{ppm}$ copper sulfate, $0.210 \mathrm{ppm}$ of erioglaucine, indicating a $30 \%$ degradation over seven days; tartrazine was not detected. 
We monitored mesocosms daily for metamorphosed individuals, presence of at least one front limb (Gosner stage 42; Gosner 1960). We brought all metamorphs to the lab and weighed them once their tails were fully resorbed (Gosner stage 46 ), to the nearest $0.001 \mathrm{~g}$ to determine mass at metamorphosis; additionally, survival and time to metamorphosis were determined as anuran data endpoints. All metamorphosed individuals were euthanized in $1 \%$ buffered MS-222. We terminated the mesocosm experiment on 25-July-2017 (experimental day 116) and 7-August-2017 (experimental day 57) after only one metamorph had been removed over a 7 day period. In 2019, the experiment was terminated on 1 August-2019 (experimental day 56), after only one metamorph had been removed over a 10 day period. We drained all mesocosms using a mesh filter and searched through the leaf litter for remaining tadpoles. In 2017, no tadpoles were found in mesocosms, and in 2019 , only two tadpoles were found.

In addition to anuran responses, we measured light availability, zooplankton abundance, and phytoplankton and periphyton abundance, to determine the indirect effects of our pond management treatments on the aquatic communities. Throughout both experiments we measured light availability, using a LI-COR PAR (photosynthetically active radiation) sensor, LI-190R, at three depths (above the surface of the water, directly under the surface of the water $[7 \mathrm{~cm}]$, and at the bottom of each mesocosm [37 cm], to determine the impact of darkening due to pond management treatment. Additionally, in 2019, we measured total zooplankton abundance twice during the experiment; 24 hours after chemical dosing and one week prior to experimental shut down. Each zooplankton sample was identified and grouped by cladocerans, copepods, and ostracods. We collected a $1 \mathrm{~L}$ composite sample of water from each mesocosm, using a polyvinyl chloride (PVC) water sampling device. Each sample was filtered using a zooplankton concentration net and preserved with $80 \%$ ethanol in a $40 \mathrm{~mL}$ glass scintillation vial.

We also measured periphyton abundance by deploying two pool noodles with glass microscope slides inserted vertically in each mesocosm; samples were collected weekly (experimental days 29, 36, 44, and 50). We collected two microscope slides and scraped each (15.24 each, 30.48 total area) using a razorblade to remove periphyton onto a Merck Millipore $0.7 \mathrm{~mm}$ pore diameter fiber glass filter and preserved in a glass scintillation vial with $15 \mathrm{ml}$ of $80 \%$ buffered acetone. We measured phytoplankton abundance weekly (experimental days $29,36,44$, and 50 ) by collecting a $100 \mathrm{~mL}$ composite sample ( $1 \mathrm{~L}$ samples were taken from each of the four cardinal directions in each mesocosm, and a $100 \mathrm{~mL}$ sample was taken from that) from each mesocosm. We filtered all samples onto a fiberglass filter and preserved them in a $40 \mathrm{~mL}$ glass scintillation vial with $15 \mathrm{~mL}$ of $80 \%$ buffered acetone. All samples were stored in a $4^{\circ} \mathrm{C}$ refrigerator for 24 hours and analyzed for chlorophyll $a$ using a Turner 10AU fluorometer. Phytoplankton and periphyton samples out of range were diluted by adding $1 \mathrm{~mL}$ of sample to fifteen milliliters of $80 \%$ buffered acetone; the resulting chlorophyll a value was multiplied by a factor of sixteen.

All statistical analyses were conducted in $\mathrm{R}$ version 3.5.1. Mesocosm was the experimental unit and all anuran species were analyzed separately for each year. We conducted an analysis of variance (ANOVA) to determine differences in mass at metamorphosis and time to metamorphosis for each anuran species among treatments. We analyzed differences in survival (metamorphs alive at end of the mesocosm experiment) across treatments using a generalized linear model (GLM) with a binomial distribution ( $R$ 
package Ime4). We conducted a repeated-measures ANOVA to determine differences in light intensity over time across treatments, and phytoplankton and periphyton abundance over time by pond management treatment and tadpole presence. Chlorophyll a abundance was log transformed to meet the assumption of normality. Furthermore, we analyzed differences in total zooplankton abundance over time by pond management treatment with a repeated-measures ANOVA. Total zooplankton abundance was rank transformed to meet the assumption of normality. We conducted a Dunnett's multiple comparison test as a post hoc analysis on all ANOVAs regardless of whether the "pond management treatment" was significant from controls.

\section{Results}

In 2017 and 2019, light intensity was significantly decreased in Aquashade treated mesocosms, compared to control ponds at both low and high depths, regardless of Aquashade concentration (Table 1, Figure 2). Copper sulfate exposure, nor the presence/absence of tadpoles (in 2019) did not significantly alter light intensity. Overall, we found no impact of pond chemical management on anuran time to metamorphosis, mass at metamorphosis, or survival for any anuran species in 2017 or 2019 (Table 2, Figure 3). In the 2019 study, gray treefrog tadpole presence was associated with a significant decrease in the abundance of both periphyton and phytoplankton chlorophyll a (Table 3, Figure 4); in contrast, pond chemical management had no impact on periphyton or phytoplankton chlorophyll a abundance. In 2019, total zooplankton abundance significantly decreased over time; however, there were no significant differences due to chemical management or tadpole presence (Table 4, Figure 5).

\section{Discussion}

Creation of aquatic habitat can benefit local wildlife (Urban and Rohem 2018) and provide ecosystem services like sediment collection (Renwick et al. 2005). However, the quality of habitat depends on management practices which influence the habitat's ecological value (Bastian et al. 2014; Nassauer et al. 2014; Kremen et al. 2018). It is imperative to understand the impact of common pond management strategies on aquatic communities because it can help inform local management recommendations and maintain valuable habitat. Overall, the results from these experiments indicate that common chemical pond management strategies, when applied at recommended doses, should have little impact on anuran metamorphosis, but also suggest that tadpoles could serve as a form of bioremediation and provide a natural ecosystem service via algal grazing.

Interestingly, it was tadpole presence that appeared to have the strongest impact on the aquatic environment. Tadpole presence resulted in a significant reduction in both periphyton and phytoplankton abundance, suggesting both are components of the gray treefrog tadpole's diet (Dickman 1968; Morin and Johnson 1988; Loman 2001), and that gray treefrog populations could control algal overgrowth. Periphyton and phytoplankton abundance were observed to initially decrease when tadpoles were present and then increased after most individuals metamorphosed due to decreased grazing pressure. Morin and Johnson (1988) observed similar patterns of periphyton and phytoplankton abundance over time due to 
variation in tadpole density and grazing pressure, further supporting tadpoles as natural grazers in aquatic ecosystems. While tadpoles are generally not considered in aquatic algal management, creating quality habitats for amphibians could allow for a natural solution with amphibians maintaining aquatic algal growth via natural grazing as an ecosystem service (Holomuzki 1998; Connelly et al. 2008). Anurans are environmental health indicators in pond ecosystems (Mendelson et al. 2006) and promoting natural anuran colonization as a pond management strategy could benefit ecosystem health and maintain anuran abundance and diversity in human-dominated systems (Connelly et al. 2008).

While we initially predicted that Aquashade would indirectly and negatively impact artificial pond communities, our results suggest Aquashade would be a safe pond management application for larval anurans. However, we did find that Aquashade reduced light penetration in the ponds, similar to other studies including Madsen et al. (1999) who observed a $10 \%$ decrease in light intensity with Aquashade application at the recommended dose (measured at $33 \mathrm{~cm}$ with a peak absorbance at $630 \mathrm{~nm}$ ) similar results were observed by Tucker and Mischke (2020). With decreased light availability, Aquashade can reduce phytoplankton and periphyton resources, thereby indirectly impacting aquatic grazers like zooplankton and tadpoles (Ludwig et al. 2010; Batt et al. 2015). While significant differences in light availability are observed from Aquashade treatment, differences in periphyton and phytoplankton abundance were not observed due to chemical management in 2019, suggesting that there was still sufficient light penetration in our mesocosms to maintain algal growth to support larval anurans (Tucker and Mischke 2020). The results of our study suggest that if individual pond managers use Aquashade at recommended doses, aquatic community should not be negatively impacted.

While copper sulfate is a known to be toxic at certain concentrations (Lande and Guttman 1973; McKim et al. 1978; Gurkan and Hayretdag 2012), we did not observe significant impacts on anuran development or survival from copper sulfate exposure. However, this is not unexpected as we chose concentrations at the recommended or lower than the recommended application dose. Moreover, studies that found negative effects on amphibians exceeded the recommended copper sulfate application rate, typically using concentrations above 0.10 ppm. For example, Garcia Munoz (2009) used 0.20 ppm and Chen et al. (2007) used $0.30 \mathrm{ppm}$ and $0.40 \mathrm{ppm}$ and found significantly increased mortality at these concentrations, which may occur when land occupants use of concentrations above recommended application rates when managing their ponds (Blaine et al. 2012).

In conclusion, the results from our experiments suggest that the use of pond management chemicals for aquatic vegetation management at recommended doses does not appear to significantly impact anuran metamorphosis, and that tadpoles can provide natural algal management in ponds. Landowners can create habitat that will attract anurans by leaving at least some natural habitat around the pond for terrestrial overwintering and foraging and by not stocking ponds with fish, which are predators of larval anurans (Porej and Hetherington 2005; Hamer and Parris 2011). These management practices could ultimately improve the local habitat matrix and increase anuran abundance and diversity across the landscape. As residential development increases it is important to further research on sustainable 
management practices that balance residential landowner preferences while improving the ecological value of the land.

\section{Declarations}

Funding: This study was funded by Miami University.

Conflicts of Interest/Competing Interests: All authors certify that they have no affiliations with or involvement in any organization or entity with any financial interest or non-financial interest in the subject matter or materials discussed in this manuscript.

Ethics Approval: The research conducted in this manuscript were covered by Miami University IACUC protocol \#827: Interactive effects of contaminants, invasive species, pathogens, and habitat manipulation on amphibian populations and community structure: how multiple stressors may contribute to amphibian declines \& influence community dynamics. Additionally, collection of egg masses was covered by the Ohio Division of Wildlife Wild Animal Permit \# 20-177 to M. D. Boone.

Consent to Participate/Publication: All authors contributed to the study conception and design. Material preparations, data collection and analysis were performed by Courtney Dvorsky, Kambrie Riddle, and Michelle Boone. The first draft of the manuscript was written by Courtney Dvorsky, and all authors commented on previous versions of the manuscript. All authors read and approved the final manuscript.

Availability of Data, Material, and Code: The datasets and code generated and/or analyzed during the current study are available from the corresponding author on reasonable request.

\section{References}

Ade C. M., Boone M. D., Puglis H. J. (2010). Effects of an insecticide and potential predators on green frogs and northern cricket frogs. Journal of Herpetology 44(4):591-600.

Batt R. D., Carpenter S.R., Cole J. J., Pace M. L., Johnson R.A., et al. (2015). Altered energy flow in the food web of an experimentally darkened lake. Ecosphere 6(3):1-23.

Bastian C. T., Coatney K. T., Mealor R. D., Taylor D. T., Meiman P. J. (2014). Priority of nature versus finances in land management attitudes of rural exurban landowners. Landscape and Urban Planning 127:65-74.

Blaine T. W., Clayton S., Robbins P., Grewal P. S. (2012). Homeowner attitudes and practices towards residential landscape management in Ohio, USA. Environmental Management 50(2):257-271.

Boone M. D., James S. M. (2003). Interactions of an insecticide, herbicide, and natural stressors in amphibian community mesocosms. Ecological Applications 13:829-841. 
Brown D.G., Johnson K. M., Loveland T.R., Theobald D.M. (2005). Rural land-use trends in the conterminous United States, 1950-2000. Ecological Applications 15(6):1851-1863.

Carey R. O., Hochmuth G. J., Martinez C. J., Boyer T. H., Dukes M. D., Toor G. S., Cisar J. L. (2013). Evaluating nutrient impacts in urban watersheds: Challenges and research opportunities. Environmental Pollution 173:138-149.

Carvalho C. S., Fernandes M. N. (2006). Effect of temperature on copper toxicity and hematological responses in the neotropical fish Prochilodus scrofa at low and high pH. Aquaculture 11(1):109-117.

Chen T. H., Gross J. A., Karasov W. H. (2007). Adverse effects of chronic copper exposure in larval northern leopard frogs (Rana pipiens). Environmental Toxicology and Chemistry 26(7):1470-1475.

Connelly S., Pringle C. M., Bixby R. J., Brenes R., Whiles M. R., Lips K. R., et al. (2008). Changes in stream primary producer communities resulting from large-scale catastrophic amphibian declines: Can smallscale experiments predict effects of tadpole loss? Ecosystems 11(8):1262-1276.

Cushman S. A. (2006). Effects of habitat loss and fragmentation on amphibians: A review and prospectus. Biological Conservation 128(2):231-240.

Dickman M. (1968). The effect of grazing by tadpoles on the structure of a periphyton community. Ecology 49(6):1188-1190.

Ewers R. M., Didham R. K. (2006). Confounding factors in the detection of species responses to habitat fragmentation. Biological Reviews of the Cambridge Philosophical Society 81(1):117-142.

García-Muñoz E., Guerrero F., Parra G. (2009). Effects of copper sulfate on growth, development, and escape behavior in Epidalea calamita embryos and larvae. Archives of Environmental Contamination and Toxicology 56(3):557-565.

Goldberg C. S., Waits L. P. (2009). Using habitat models to determine conservation priorities for pondbreeding amphibians in a privately-owned landscape of northern Idaho, USA. Biological Conservation 142(5):1096-1104.

Gosner K. L. (1960). A simplified table for staging anuran embryos and larvae with notes on identification. Herpetologica 16(3):183-190.

Gürkan M., Hayretdağ S. (2012). Morphological and histological effects of copper sulfate on the larval development of green toad, Bufo viridis. Turkish Journal of Zoology 36(2):231-240.

Hansen A. J., Knight R. L., Marzluff J. M., Powell S., Brown K., et al. (2005). Effects of exurban development on biodiversity: Patterns, mechanisms, and research needs. Ecological Applications 15:1893-1905. 
Hamer A. J., Parris K. M., Hamer, J. (2011). Local and landscape determinants of amphibian communities in urban ponds. Ecological Applications 21(2):378-390.

Holomuzki J. R. (1998). Grazing effects by green frog tadpoles (Rana clamitans) in a woodland pond. Journal of Freshwater Ecology 13(1):1-8.

Kremen C., Merenlender A. M. (2018). Landscapes that work for biodiversity and people. Science 362(6412).

Lande S. P., Guttman S. I. (1973). The effects of copper sulfate on the growth and mortality rate of Rana pipiens tadpoles. Herpetologica 29(1):22-27.

Locke D. H., Polsky C., Grove J. M., Groffman P. M., et al. (2019). Residential household yard care practices along urban-exurban gradients in six climatically-diverse U.S. metropolitan areas. PLoS ONE 14(11):1-15.

Loman J. (2001). Effects of tadpole grazing on periphytic algae in ponds. Wetlands Ecology and Management 9(2):135-139.

Loman J., Lardner B. (2006). Does pond quality limit frogs Rana arvalis and Rana temporaria in agricultural landscapes? A field experiment. Journal of Applied Ecology 43(4):690-700.

Ludwig G. M., Perschbacher P., Edziyie R. (2010). The effect of the dye Aquashade(R) on water quality, phytoplankton, zooplankton and sunshing bass, Morone chrysops $\times$ M. saxatilis, fingerling production in fertilized culture ponds. Journal of the World Aquaculture Society 41:40-49.

Lynch W. E. J. (2009). Chemical control of aquatic plants. The Ohio State University: Agriculture and Natural Resources 1-8.

Madsen J. D., Getsinger K. D., Stewart R. M., Skogerboe J. G., et al. (1999). Evaluation of transparency and light attenuation by Aquashade ${ }^{\mathrm{TM}}$. Lake and Reservoir Management 15(2):142-147.

Mallory M. A., Richardson J. S. (2005). Complex interactions of light, nutrients, and consumer density in a stream periphyton-grazer (tailed frog tadpoles) system. Journal of Animal Ecology 74(6):1020-1028.

Martini N. F., Nelson K. C., Hobbie S. E., Baker L. A. (2015). Why "Feed the Lawn"? Exploring the influences on residential turf grass fertilization in the Minneapolis-Saint Paul metropolitan area. Environment and Behavior 47(2):158-183.

McKee J. K., Sciull, P. W., Fooce D. C., Waite T. A. (2003). Forecasting global biodiversity threats associated with human population growth. Biological Conservation 115(1):161-64.

McKim J. M., Eaton J. G., Holcombe G. W. (1978). Metal toxicity to embryos and larvae of eight species of freshwater fish-II: Copper. Bulletin of Environmental Contamination and Toxicology 19(1): 608-616. 
Mendelson J. R., Lips K. R., Gagliardo R. W., Rabb G. B., et al. (2006). Confronting amphibian declines and extinctions. Science 313(5783).

Morin P. J., Johnson E. A. (1988). Experimental studies of asymmetric competition among anurans. Oikos 53(3):398-407.

Nassauer J. I., Cooper D. A., Marshall L. L., Currie W. S., et al. (2014). Parcel size related to household behaviors affecting carbon storage in exurban residential landscapes. Landscape and Urban Planning 129:55-64.

Peltzer P. M., Lajmanovich R. C., Sánchez-Hernandez J. C., et al. (2008). Effects of agricultural pond eutrophication on survival and health status of Scinax nasicus tadpoles. Ecotoxicology and Environmental Safety 70(1):185-197.

Porej, D., \& Hetherington, T. E. (2005). Designing wetlands for amphibians: The importance of predatory fish and shallow littoral zones in structuring of amphibian communities. Wetlands Ecology and Management 13(4):445-455.

Pryor G. S. (2003). Growth rates and digestive abilities of bullfrog tadpoles (Rana catesbeiana) fed algal diets. Journal of Herpetology 37(3):560-566.

Relyea R. A. (2005). The impact of insecticides and herbicides on the biodiversity and productivity of aquatic communities. Ecological Applications 15(2):618-627.

Renwick W. H., Smith S. V., Bartley J. D., Buddemeier R. W. (2005). The role of impoundments in the sediment budget of the conterminous United States. Geomorphology 71:99-111.

Robinson D. T. (2012). Land-cover fragmentation and configuration of ownership parcels in an exurban landscape. Urban Ecosystems 15(1):53-69.

Rowland F. E., Rawlings M. B., Semlitsch R. D. (2017). Joint effects of resources and amphibians on pond ecosystems. Oecologia 183(1):237-247.

Smith S. V., Renwick W. H., Bartley J. D., Buddemeier R. W. (2002). Distribution and significance of small, artificial water bodies across the United States landscape. Science of the Total Environment 299:21-36.

Suski J. G., Swan C. M., Salice C. J., Wahl C. F. (2018). Effects of pond management on biodiversity patterns and community structure of zooplankton in urban environments. Science of the Total Environment 619-620:1441-50

Theobald D. M. (2004). Placing exurban land-use change in a human modification framework. Frontiers in Ecology and the Environment 2(3):139-144. 
Tucker C. S., Mischke C. C. (2020). The pond dye, Aquashade, does not prevent cyanobacterial off-flavors in pond-grown channel catfish. North American Journal of Aquaculture 82(1):101-107.

Urban M. C., Roehm R. (2018). The road to higher permanence and biodiversity in exurban wetlands. Oecologia 186(1):291-302.

US. EPA. (2005) Aquashade: HED Chapter of the Reregistration Eligibility Decision Document US. EPA. (2013) Copper Sulfate Fine Crystals.

Vonesh J. R., Kraus J. M., Rosenberg J. S., Chase J. M. (2009). Predator effects on aquatic community assembly: Disentangling the roles of habitat selection and post-colonization processes. Oikos 118(8):1219-1229.

Walston L. J., Mullin S. J. (2007). Responses of a pond-breeding amphibian community to the experimental removal of predatory fish. American Midland Naturalist 157(1):63-73.

\section{Tables}

Table 1 Summary of a repeated measures analysis of variance (ANOVA) for light intensity at varying depths in mesocosms in 2017. Significant effects $(\alpha \leq 0.05)$ are in bold text 
Year Response Variable

2017 Average Light Above

Average Light at $7 \mathrm{~cm}$

Average Light at $37 \mathrm{~cm}$

2019 Average Light Above

Average Light at $7 \mathrm{~cm}$

Average Light at $37 \mathrm{~cm}$

Source of Variation $d f \quad F$ value $p$-value

Mesocosms Between Subjects

$\begin{array}{llll}\text { Treatment } & 4 & 1.023 & 0.419\end{array}$

Within Subjects

$\begin{array}{llll}\text { Date } & 1 & 10.012 & \mathbf{0 . 0 0 2}\end{array}$

$\begin{array}{llll}\text { Treatment*Date } \quad 4 & 0.474 & 0.755\end{array}$

Between Subjects

$\begin{array}{llll}\text { Treatment } & 4 & 3.329 & \mathbf{0 . 0 3 0}\end{array}$

Within Subjects

Date $\quad 1 \quad 39.66 \quad<0.001$

Treatment*Date $\quad 4 \quad 0.150 \quad 0.963$

Between Subjects

$\begin{array}{llll}\text { Treatment } & 4 & 7.204 & \mathbf{0 . 0 0 1}\end{array}$

Within Subjects

$\begin{array}{llll}\text { Date } & 1 & 39.66 & <\mathbf{0 . 0 0 1} \\ \text { Treatment*Date } & 4 & 0.150 & 0.901\end{array}$

Mesocosms Between Subjects

$\begin{array}{llll}\text { Management } & 2 & 4.675 & \mathbf{0 . 0 2 1}\end{array}$

$\begin{array}{llll}\text { Tadpole } & 1 & 0.054 & 0.818\end{array}$

Within Subjects

$\begin{array}{llll}\text { Date } & 1 & 65.648 & \mathbf{< 0 . 0 0 1} \\ \text { Management*Date } & 2 & 1.811 & 0.168 \\ \text { Tadpoles*Date } & 5 & 0.120 & 0.988\end{array}$

Between Subjects

Management $2 \quad 2 \quad 15.98 \quad<0.001$

$\begin{array}{llll}\text { Tadpole } & 1 & 0.490 & 0.491\end{array}$

Within Subjects

$\begin{array}{llll}\text { Date } & 1 & 227.147 & \mathbf{< 0 . 0 0 1} \\ \text { Management*Date } & 2 & 2.816 & 0.064 \\ \text { Tadpole*Date } & 5 & 0.805 & 0.549\end{array}$

Between Subjects

$\begin{array}{llll}\text { Management } & 2 & 40.2 & \mathbf{< 0 . 0 0 1} \\ \text { Tadpole } & 1 & 0.143 & 0.709\end{array}$

Within Subjects

$\begin{array}{llll}\text { Date } & 1 & 232.91 & <0.001 \\ \text { Management*Date } & 2 & 14.85 & <0.001\end{array}$


Table 2 Summary of analysis of variance (ANOVA) for time to metamorphosis (experimental days), mass at metamorphosis (grams) and survival for all anurans by management treatment for all species in 2017 and 2019. American toad time to metamorphosis was rank transformed to meet the assumptions of normality

\begin{tabular}{cccccc}
\hline Species & Year & Response Variable & F statistic & $d f$ & $p$-value \\
\hline American Toad & 2017 & Time & 2.451 & 4,20 & 0.079 \\
& & Mass & 0.332 & 4,20 & 0.853 \\
\hline Northern Leopard Frog & 2017 & Survival & 0.248 & 4,20 & 0.907 \\
\hline & & Time & 0.503 & 4,20 & 0.734 \\
\hline Cope's Gray Treefrog & 2017 & Mass & 1.317 & 4,20 & 0.298 \\
\hline & & Survival & 1.650 & 4,20 & 0.201 \\
\hline & & Time & 1.313 & 4,20 & 0.299 \\
\hline Cope's Gray Treefrog & 2019 & Mass & 0.843 & 4,20 & 0.515 \\
\hline & & Time & 3.199 & 2,9 & 0.089 \\
\hline & & Mass & 0.697 & 2,9 & 0.523 \\
\hline
\end{tabular}

Table 3 Summary of a repeated measures analysis of variance (ANOVA) on periphyton and phytoplankton abundance (chlorophyll a) by pond management treatment, presence of tadpoles, date, and interactions. Periphyton and phytoplankton chlorophyll a was log transformed to meet assumptions of normality. Significant effects $(\alpha \leq 0.05)$ are in bold text 
Source of Variation

Df $\begin{array}{ll}F \\ \text { value`2 }\end{array} \quad p$-value

Average periphyton cholorphyll $a$
Average phytoplankton chlorophyll a
Between Subjects

Management

$2 \quad 0.209$

0.599

Tadpoles

14.803

0.003

Management*Tadpoles

$2 \quad 2.945$

0.078

Within Subjects

Date

Management*Date

$3 \quad 147.138<0.001$

Tadpoles*Date

$\begin{array}{ll}6 & 3.254\end{array}$

0.776

Management*Tadpoles*Date

0.652

0.383

Between Subjects

$\begin{array}{llll}\text { Management } & 2 & 0.747 & 0.483 \\ \text { Tadpoles } & 1 & 4.173 & 0.057 \\ \text { Management*Tadpoles } & 2 & 0.602 & 0.559\end{array}$

Within Subjects

Date $3 \quad 2.037$

0.120

Management*Date

$6 \quad 1.096$

0.377

Tadpoles*Date

$3 \quad 0.921$

0.437

Management*Tadpoles*Date

Table 4 Summary of a repeated measures analysis of variance (ANOVA) on zooplankton abundance by herbicide treatment, presence of tadpoles, date, and interactions. Total zooplankton abundance data was rank transformed to meet assumptions of normality. Significant effects $(\alpha \leq 0.05)$ are in bold text

\begin{tabular}{lllll}
\hline Response Variable & Source of Variation & $d f$ & $F$ value & $p$-value \\
\hline Total Number of Zooplankton & Between Subjects & & & \\
& Management & 2 & 1.624 & 0.225 \\
& Tadpoles & 1 & 0.002 & 0.968 \\
& Management*Tadpoles & 2 & 2.071 & 0.155 \\
& Within Subjects & & & \\
\hline & Date & 1 & 247.686 & $<0.001$ \\
\hline & Management*Date & 2 & 2.152 & 0.145 \\
\hline & Tadpoles*Date & 1 & 3.452 & 0.080 \\
\hline & Management*Tadpoles*Date & 2 & 4.780 & 0.022 \\
\hline
\end{tabular}


Figures
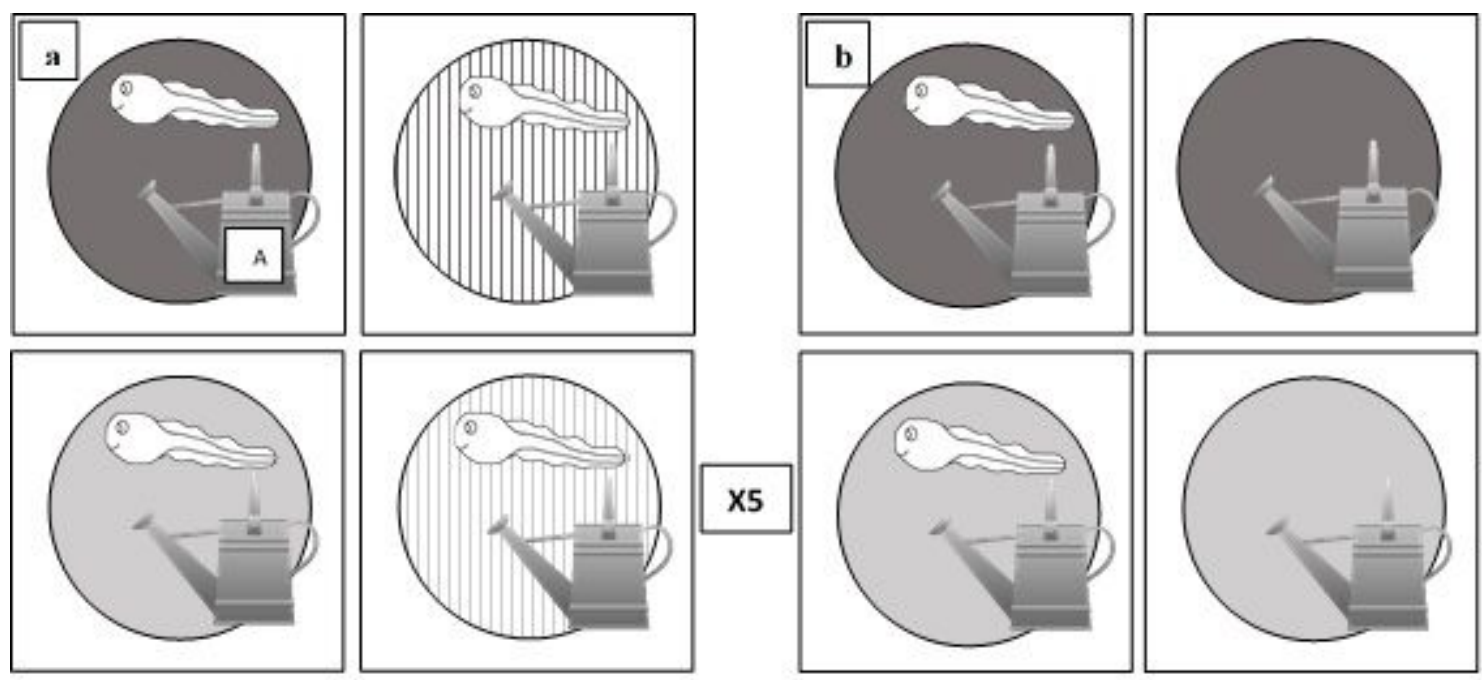

X4
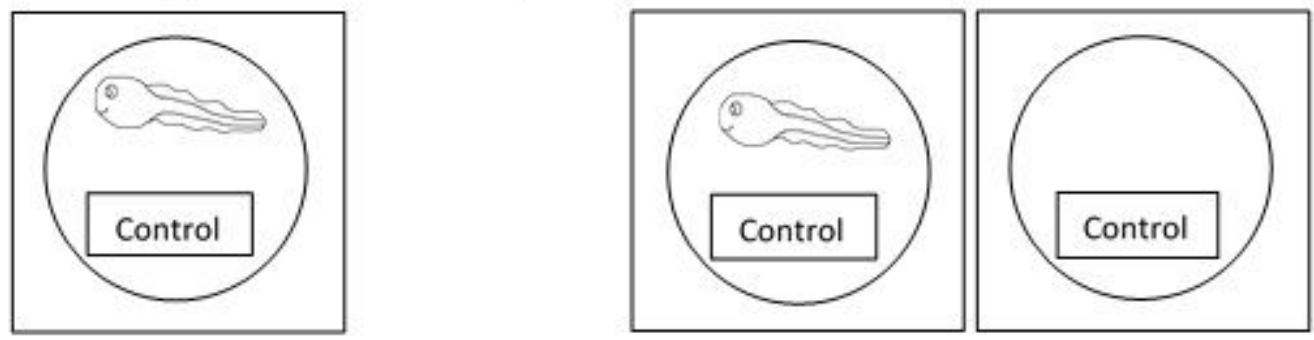

\section{Figure 1}

This diagram represents the experimental design for 2017 (a) and 2019 (b). In 2017 there were 5 treatments, 2 pond management treatments (Aquashade [A] and copper sulfate [C]) and 2 doses (high and low), with one control with no treatment; each treatment had 5 mesocosm replicates. In 2019, there were six total treatments: 2 pond management treatments (Aquashade and copper sulfate), and 2 tadpole treatments (present or absent), and 2 control treatments; each treatment had four mesocosm replicates 

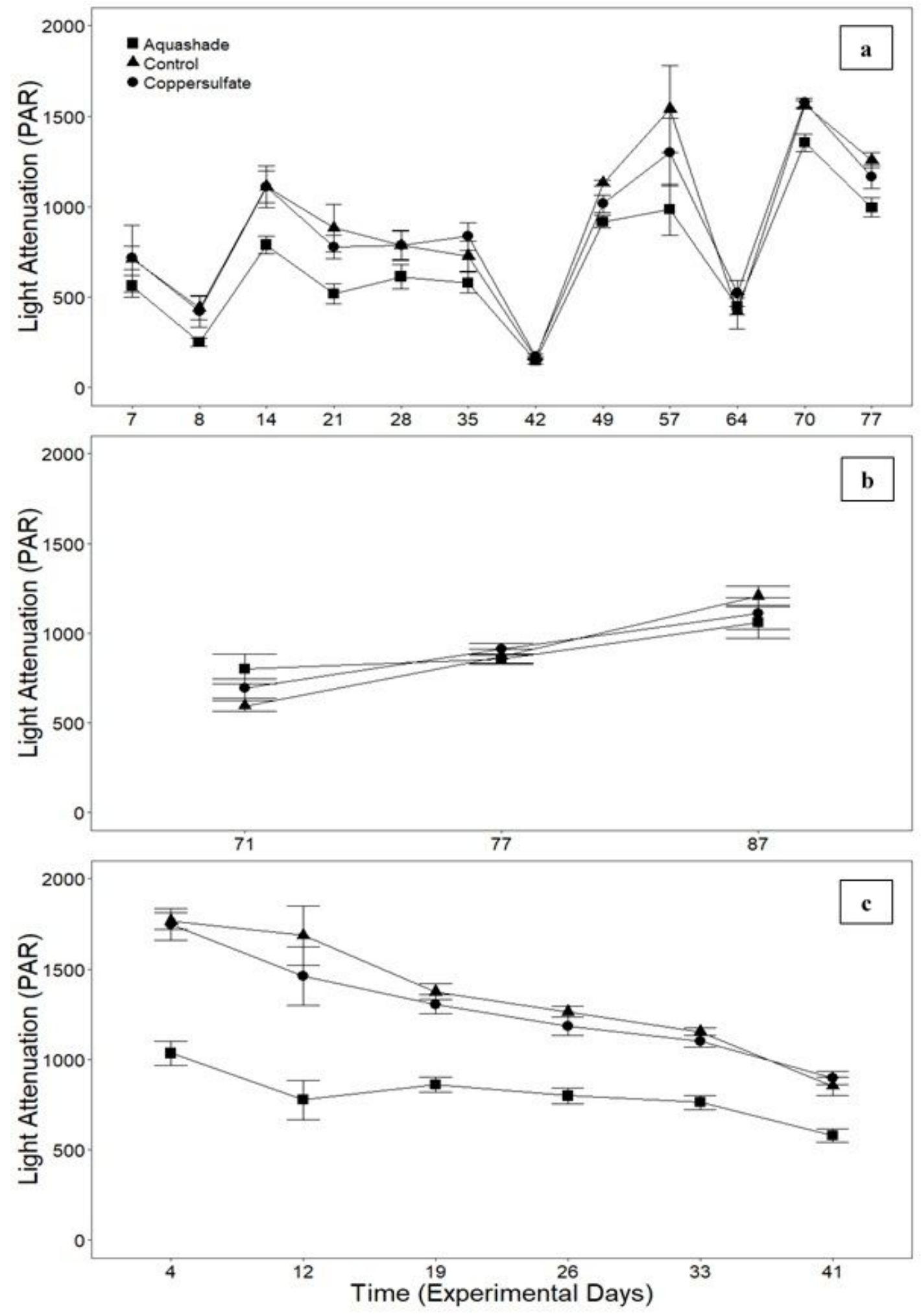

Figure 2

Light attenuation at the bottom of the mesocosm $(0.37 \mathrm{~cm})$ by pond management treatments. Mesocosms set up during spring breeders 2017 (a), summer 2017 mesocosms (b), and 2019 mesocosms (c). Significant differences were observed between Aquashade and control treatments, with Aquashade being significantly decreased 


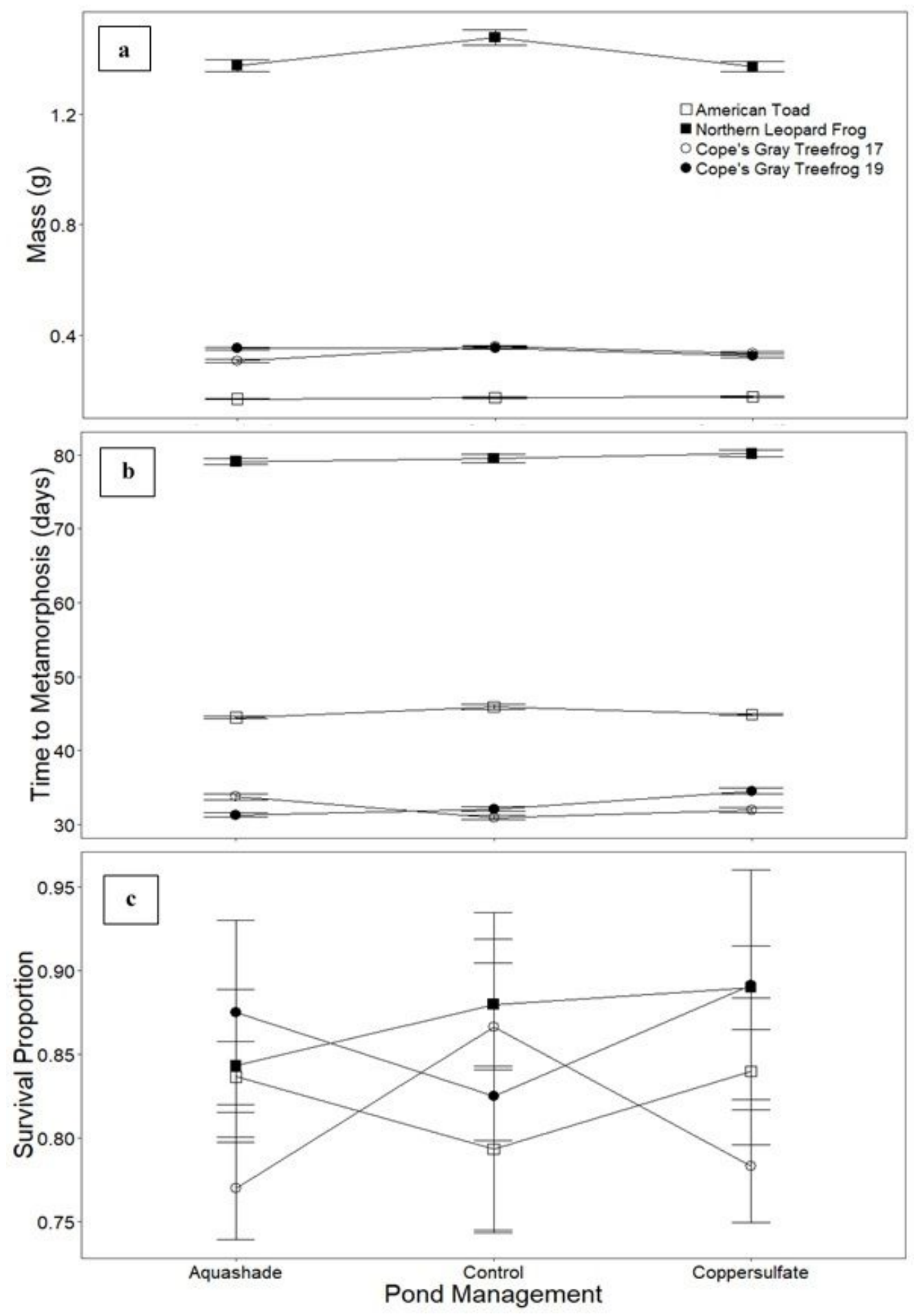

\section{Figure 3}

Represents anuran endpoints for both experiments; Mass at metamorphosis (a), time to metamorphosis (b), and survival (c). No significant differences were observed in any anuran endpoint regardless of species, pond management treatment or year 

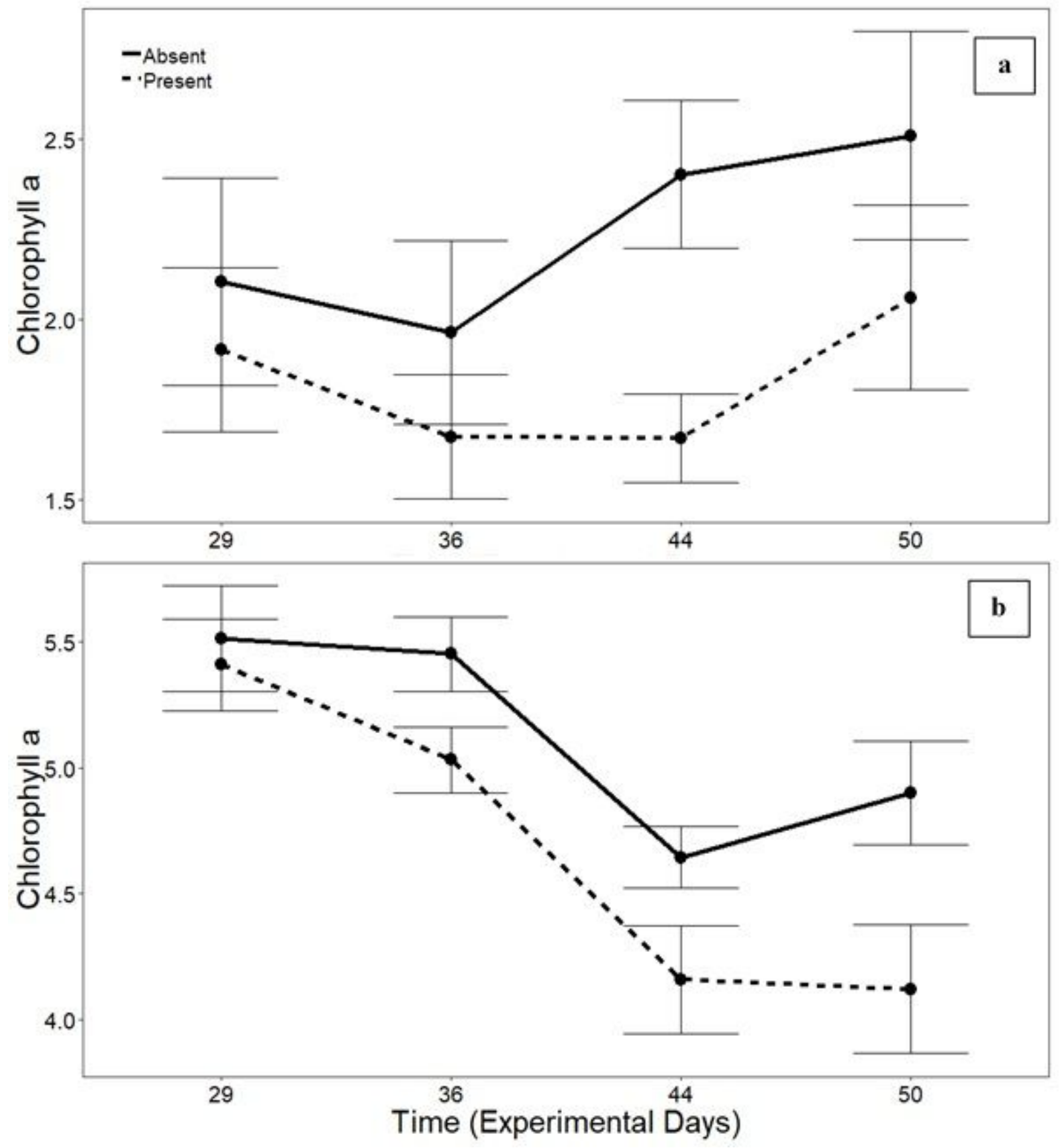

Figure 4

Represents phytoplankton (a) and periphyton abundance (b) with tadpole presence over time (experimental days). Tadpole presence significantly decreased periphyton and phytoplankton abundance over time 


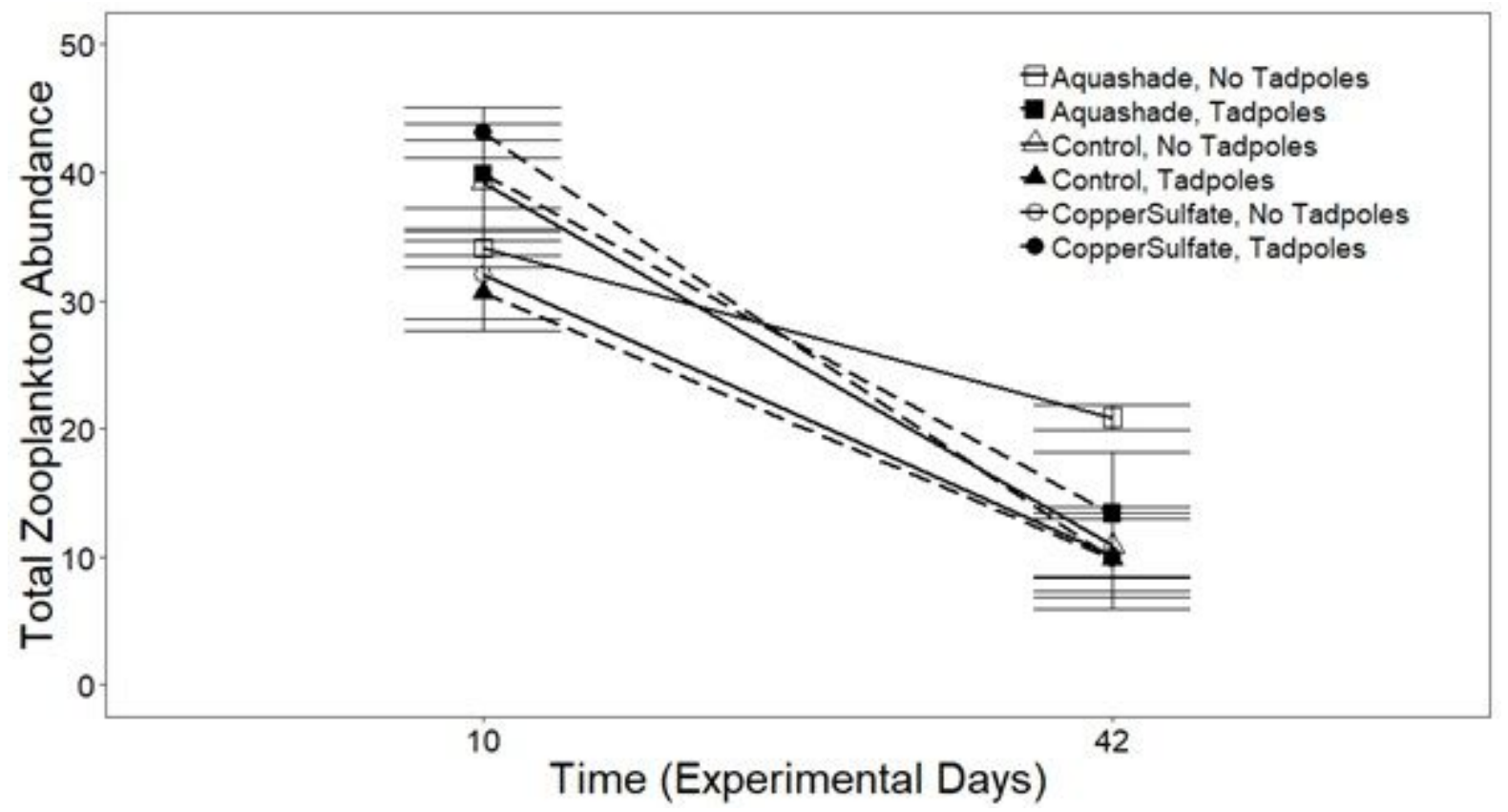

Figure 5

Represents total zooplankton abundance over time (experimental days) by treatment. Overall, zooplankton abundance decreased over time but did not differ due to pond chemical treatment or tadpole presence 